\title{
Surveillance of COVID-19 in the General Population Using an Online Questionnaire: Report From 18,161 Respondents in China
}

Hongxing Luo ${ }^{1}$, MD; Yongchan Lie ${ }^{2}$, MPH; Frits W Prinzen ${ }^{1}$, DPhil

${ }^{1}$ Department of Physiology, Cardiovascular Research Institute Maastricht, Maastricht University, Maastricht, Netherlands

${ }^{2}$ Department of Health Ethics and Society, Faculty of Health Medicine and Life Sciences, Maastricht University, Maastricht, Netherlands

Corresponding Author:

Hongxing Luo, MD

Department of Physiology, Cardiovascular Research Institute Maastricht

Maastricht University

Welsdaal $150 \mathrm{C}$

Maastricht, 6228JG

Netherlands

Phone: 31685704703

Email: h.luo@maastrichtuniversity.nl

\section{Abstract}

Background: The recent outbreak of the coronavirus disease (COVID-19) has become an international pandemic. So far, little is known about the role of an internet approach in COVID-19 participatory surveillance.

Objective: The aim of this study is to investigate whether an online survey can provide population-level information for observing prevalence trends during the early phase of an outbreak and identifying potential risk factors of COVID-19 infection.

Methods: A 10-item online questionnaire was developed according to medical guidelines and relevant publications. It was distributed between January 24 and February 17, 2020. The characteristics of respondents and temporal changes of various questionnaire-derived indicators were analyzed.

Results: A total of 18,161 questionnaires were returned, including 6.45\% ( $\mathrm{n}=1171)$ from Wuhan City. Geographical distributions of the respondents were consistent with the population per province $\left(R^{2}=0.61, P<.001\right)$. History of contact significantly decreased with time, both outside Wuhan City $\left(R^{2}=0.35, P=.002\right)$ and outside Hubei Province $\left(R^{2}=0.42, P<.001\right)$. The percentage of respondents reporting a fever peaked around February $8\left(R^{2}=0.57, P<.001\right)$ and increased with a history of contact in the areas outside Wuhan City (risk ratio 1.31, 95\% CI 1.13-1.52, $P<.001$ ). Male sex, advanced age, and lung diseases were associated with a higher risk of fever in the general population with a history of contact.

Conclusions: This study shows the usefulness of an online questionnaire for the surveillance of outbreaks like COVID-19 by providing information about trends of the disease and aiding the identification of potential risk factors.

(JMIR Public Health Surveill 2020;6(2):e18576) doi: 10.2196/18576

\section{KEYWORDS}

coronavirus; surveillance; syndromic surveillance; participatory surveillance; online questionnaire; Wuhan; COVID-19

\section{Introduction}

The recent outbreak of the coronavirus disease (COVID-19) has caused over 752,000 confirmed cases and 36,000 deaths as of March 30, 2020 [1-4]. Despite a proactive policy of identifying and treating patients with infected symptoms, it remains resource intensive to screen the general population that is at risk for infection $[5,6]$. Moreover, inequality of health care systems among different areas brings challenges to cover remote areas, which are also at risk of the COVID-19 infection.
Therefore, a new way of surveilling the general population could contribute to our understanding of COVID-19 [7]. The wide use of the internet throughout China, and in the rest of the world, may be sufficient to provide such information. Participatory disease surveillance has been increasingly investigated in recent years as a promising tool to complement traditional facility-based surveillance platforms [8]. It has the advantage of providing quick coverage of a large population during a disease outbreak. Therefore, an online survey may be valuable in monitoring disease trends in communities and providing information for making policies. 
In this paper, we report the results of the first online questionnaire about COVID-19, released on January 24 and with data collected up to February 17, 2020. Our study aims to investigate how a history of contact and fever (both defined according to relevant medical guidelines) have evolved during the early phase of government lockdown policies and whether an online questionnaire can be used to identify certain risk factors related to fever among those reporting history of contact.

\section{Methods}

\section{Questionnaire Development and Distribution}

The first version of the questionnaire was developed on January 24, 2020. By that time, little evidence was known about COVID-19. Our anonymous questionnaire was primarily developed from the following 3 sources: (1) the Diagnosis and Treatments of COVID-19 (Third Version) guideline; (2) clinical courses of the first 17 death cases, both of which were released by the National Health Commission of China; and (3) the article that first analyzed the clinical features of 41 cases of COVID-19 [9-11]. The guideline requires a suspected case to satisfy the following criteria: any history of contact including living in Wuhan or having travelled to Wuhan within 2 weeks of disease onset, being in contact with any person with a fever and respiratory symptoms from Wuhan within 2 weeks of disease onset, or belonging to a cluster of infected cases; and clinical manifestations including a fever (defined as a body temperature $\geq 37.3{ }^{\circ} \mathrm{C}\left[99.1^{\circ} \mathrm{F}\right]$ ), imaging evidence of COVID-19, normal white blood cell count, or leukopenia or lymphopenia. A confirmed case is further established by positive findings of real time polymerase chain reaction or viral gene sequencing. The descriptions of the guideline are in good consistency with the clinical features of the first 17 death cases and later 41 infected cases reported on January 24, 2020 [9,10]. Therefore, our questionnaire evaluated the risk of COVID-19 in the general population from the following aspects:

1. History of contact: living in Wuhan, having travelled to Wuhan in the past 2 weeks, having any close contact (lived, studied, or worked together, or had any other close contact) in the past 2 weeks with a person with a fever and cough who came from Wuhan, or being in a workplace, school, or family that has at least 2 confirmed cases. Other history of contact with wildlife animals within 2 weeks of disease onset was also considered.

2. Body temperature: having a fever with a body temperature higher than $37.3^{\circ} \mathrm{C}\left(99.1^{\circ} \mathrm{F}\right)$

3. Symptoms: we classified symptoms by their relative importance into the following 3 groups: (1) chief symptoms related to pulmonary infection (ie, cough without sputum or with little sputum) and shortness of breath; (2) secondary symptoms related to systemic changes probably caused by viral infection (ie, fatigue, headache, and myalgia); and (3) probably unrelated symptoms (ie, nasal obstruction, rhinorrhea, sneezing, sore throat, and diarrhea).

4. Comorbidities: Lung diseases, cardiovascular diseases, hypertension, diabetes, stroke, and chronic kidney dysfunction

5. Basic information: age and gender
We did not include laboratory examinations (eg, real time polymerase chain reaction, lymphopenia, white blood cell count) or thoracic imaging results (eg, multiple patchy consolidation and interstitial changes) in our questionnaire because, in general, these would unlikely be obtained by the general population.

By February 17, 2020, we had developed and released three versions of the Chinese questionnaires to the public. They were essentially similar, with the following three major revisions:

1. We divided the age group of $\leq 40$ years used in the first version into age groups of $\leq 30$ years and $31-40$ years in the following two versions for better risk stratification.

2. History of contact with wildlife animals was removed from the third version, as we considered it to have a low value for diagnosis in the general population.

3. The question initially included for evaluating shortness of breath, "I feel extremely short of breath when climbing upstairs or walking at a fast speed" (modified from the Medical Research Council Breathlessness scale), was removed from the third version and added as an item named "shortness of breath" to the question about symptoms of COVID-19. This was done because we found an exceptionally high percentage of respondents reporting shortness of breath in the first 2 versions of the questionnaires (26.5\% and $32.9 \%$, respectively).

After completing the questionnaire, the respondents would be classified into one of the following 4 risk groups and given different suggestions:

1. High-risk group having history of contact and fever: it was suggested that they measure their body temperature after 30 minutes and immediately visit the hospital to screen for a potential COVID-19 infection.

2. Moderate-risk group having history of contact but without fever: it was suggested that they monitor their body temperature daily and get screened for a potential COVID-19 infection if fever or respiratory symptoms occurred.

3. Low-risk group without history of contact but with fever: this group probably had a common cold, and it was suggested that they make an appointment with a general practitioner for help, if necessary.

4. Very low-risk group without history of contact or fever: they were unlikely to have COVID-19 at the time they completed the questionnaire, and it was suggested that they take necessary measures such as putting on a facemask to prevent the infection.

The questionnaire was developed using a professional online questionnaire website Wenjuanxing (Questionnaire Star) [12]. It is the most popular website for online surveys in China with over 4.2 billion questionnaires recycled and over 59 million users as of February 21, 2020. Questionnaires were distributed online by WeChat (the most popular instant messaging app in China) and sharing the link of the questionnaire. Since our aim was to have an overview of situations in China during the COVID-19 outbreak, we did not target any specific groups of respondents. Distribution and filling out the questionnaires were voluntary, making our study a convenience sampling study. 
According to the World Health Organization Guidelines on Ethical Issues in Public Health Surveillance, a surveillance study in emergency outbreak situations is exempted from ethical review and oversight [13]. Indeed, our online questionnaire was designed on January 23, 2020, when the lockdown of Wuhan City was officially announced and released on January 24 , so it could not await the formal approval of an ethical review committee. All users were informed at the beginning of the questionnaire that their questionnaire data would be used only for medical education and research purposes. If the informed consent was rejected by the users, they could still continue the questionnaire and obtain their results.

\section{Data Collection}

The questionnaire was released on January 24, 2020, and recycled on February 17. All questionnaire results were downloaded from the website for our analysis. In addition to the items of the questionnaire, the downloaded data also included the date of submission for all respondents as well as the respondents' location at the city level.

We also collected population data of each province from China Statistical Abstract 2019 published by the National Bureau of Statistics of China [14]. The number of confirmed cases was followed up with on a daily basis since the release of the questionnaire using the NetEase News website, the largest Chinese hub for real time collection of data and news related to COVID-19 [15]. The statistics of confirmed cases per province used in this study were collected until midnight of February 11; at that time, clinically diagnosed cases without positive real time polymerase chain reaction results were also included in the official confirmed number of cases.

\section{Statistical Analysis}

Count data were expressed as number (percentage). Skewed continuous data (time to complete questionnaire) were expressed as median (IQR). Geographical distributions were drawn using
Microsoft Excel Visual Basic. A Pearson correlation analysis was used to analyze the relationship between two variables of interest (mainly between date and percentage of respondents of interest per day). Comparison of respondents' basic characteristics between the inside and outside of Wuhan was performed using a chi-square test or a Fisher exact test if the sample size was <40. Risk of fever in respondents with history of contact was evaluated using a risk ratio (RR) and $95 \%$ CI. All statistical analyses were performed using Stata 14.0 (StataCorp) and MATLAB R2018b (MathWorks). Statistical significance was defined as a two-tailed $P$ value <.05.

\section{Results}

\section{Questionnaire Respondents}

By February 17, 2020 at 2:33 AM, a total of 19,449 individuals completed the questionnaires, $98.02 \%(n=19,064)$ from China. After removing 385 questionnaires from overseas countries, 575 lacking informed consent, 55 missing age, 31 missing temperature, 38 missing comorbidities, and 4 missing symptoms information, 18,161 anonymous questionnaires were analyzed. Overall, it took median 52 (IQR 41-67) seconds to complete the questionnaire. Most questionnaires were accessed by clicking on the link of the questionnaire $(n=11,337,62.42 \%)$ and by visiting the WeChat mini-app $(n=6800,37.44 \%)$.

\section{Geographical Distributions}

Figure 1A shows the geographical distributions of the questionnaire respondents in China. The questionnaire covered all 34 province-level administrative regions. For Hubei Province, $68.48 \%(n=1171 / 1710)$ of the respondents came from Wuhan City, which was most affected by COVID-19. A positive relation was found between the number of respondents and the population size per province (Figure 1B), demonstrating good coverage of the questionnaire across China. 
Figure 1. A) Geographical distributions of questionnaire respondents in China. B) A positive correlation between the number of respondents and the size of the population of each province.
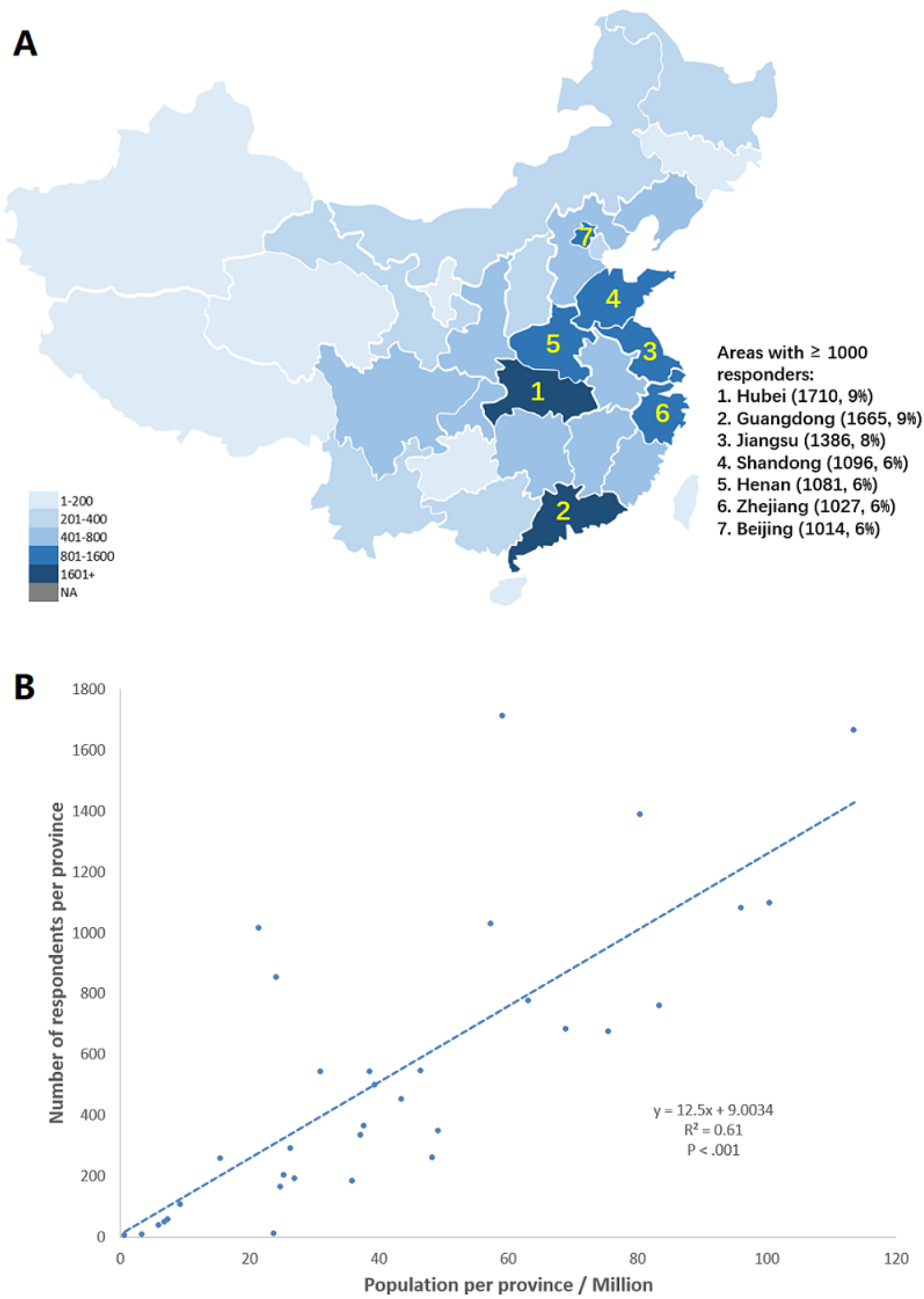

\section{Basic Characteristics}

Table 1 summarizes the demographics and basic characteristics of respondents. The population in Wuhan had similar ages and comorbidities compared with those outside of Wuhan. Age was negatively correlated with the number of respondents $\left(R^{2}=0.95\right.$, $P<.001)$. As expected, history of contact was more frequent among the respondents living in Wuhan. The percentage of fever was significantly lower among respondents inside versus outside Wuhan. Symptoms were reported in a rather high percentage of respondents. When restricting the symptoms to at least one main symptom and one secondary symptom, the number of respondents with symptoms dropped to $12.62 \%$ $(n=2292 / 18,161)$. 
Table 1. Demographics and basic characteristics of respondents.

\begin{tabular}{|c|c|c|c|c|}
\hline Characteristics & $\begin{array}{l}\text { All respondents } \\
(\mathrm{N}=18,161), \mathrm{n}(\%)\end{array}$ & Wuhan (n=1171), n (\%) & $\begin{array}{l}\text { Outside Wuhan } \\
(\mathrm{n}=16,990), \mathrm{n}(\%)\end{array}$ & $P$ value \\
\hline Women & $10,801(59.47)$ & $762(65.07)$ & $10,039(59.09)$ & $<.001$ \\
\hline \multicolumn{5}{|l|}{ Age (years) } \\
\hline$\leq 30$ & $12,504(68.85)$ & $782(66.78)$ & $11722(68.99)$ & .11 \\
\hline $31-40$ & 3757 (20.69) & $282(24.08)$ & $3475(20.45)$ & .003 \\
\hline $41-50$ & $1154(6.35)$ & $70(5.98)$ & $1084(6.38)$ & .59 \\
\hline $51-60$ & $532(2.93)$ & $28(2.39)$ & $504(2.97)$ & .26 \\
\hline $61-70$ & $147(0.81)$ & $6(0.51)$ & $141(0.83)$ & .24 \\
\hline$\geq 71$ & $67(0.37)$ & $3(0.26)$ & $64(0.38)$ & .51 \\
\hline Comorbidity & $1593(8.77)$ & $95(8.11)$ & $1498(8.82)$ & .41 \\
\hline Hypertension & $655(3.61)$ & $38(3.25)$ & $617(3.63)$ & .49 \\
\hline Lung diseases & $468(2.58)$ & $24(2.05)$ & $444(2.61)$ & .24 \\
\hline Cardiovascular diseases & $375(2.06)$ & $21(1.79)$ & $354(2.08)$ & .50 \\
\hline Diabetes & $223(1.23)$ & $16(1.37)$ & $207(1.22)$ & .66 \\
\hline Chronic kidney disease & $135(0.74)$ & $5(0.43)$ & $130(0.77)$ & .19 \\
\hline Stroke & $34(0.19)$ & $4(0.34)$ & $30(0.18)$ & .21 \\
\hline History of contact & $2631(14.49)$ & $1171(100.00)$ & $1460(8.59)$ & $<.001$ \\
\hline $\begin{array}{l}\text { Living in Wuhan now or having gone to Wuhan in the } \\
\text { past } 2 \text { weeks }\end{array}$ & $1950(10.74)$ & $1171(100.00)$ & $779(4.59)$ & $<.001$ \\
\hline $\begin{array}{l}\text { Contact with a person with fever and cough from Wuhan } \\
\text { in the past } 2 \text { weeks }\end{array}$ & $938(5.16)$ & $298(25.45)$ & $640(3.77)$ & $<.001$ \\
\hline $\begin{array}{l}\text { At least } 2 \text { confirmed cases in workplace, school, or } \\
\text { family }\end{array}$ & $532(2.93)$ & $122(10.42)$ & $410(2.41)$ & $<.001$ \\
\hline Symptoms & $11,796(64.95)$ & $699(59.69)$ & $11,097(65.31)$ & $<.001$ \\
\hline Fever & $1653(9.10)$ & $56(4.78)$ & $1597(9.40)$ & $<.001$ \\
\hline Cough & $5242(28.86)$ & $314(26.81)$ & $4928(29.00)$ & .11 \\
\hline Shortness of breath & $4393(24.19)$ & $263(22.46)$ & $4130(24.31)$ & .15 \\
\hline Nasal obstruction, rhinorrhea, or sneezing & $4376(24.10)$ & $237(20.24)$ & $4139(24.36)$ & .001 \\
\hline Sore throat & $3397(18.70)$ & $201(17.16)$ & $3196(18.81)$ & .16 \\
\hline Fatigue & 3245 (17.87) & $148(12.64)$ & $3097(18.23)$ & $<.001$ \\
\hline Headache or myalgia & $2072(11.41)$ & $87(7.43)$ & $1985(11.68)$ & $<.001$ \\
\hline Diarrhea & $1360(7.49)$ & $70(5.98)$ & $1290(7.59)$ & .04 \\
\hline
\end{tabular}

\section{History of Contact}

A history of contact was reported by more than one-eighth of respondents. However, the high percentage might have been confounded considering that all respondents living in Wuhan City had a history of contact according to the definition of the official guideline, so we excluded these respondents from our analysis and divided the remaining respondents by every 8 days into 3 phases: phase 1 was from January 24 to 31, phase 2 was from February 1 to 8, and phase 3 was from February 9 to 16
Despite heterogeneous responses of different provinces, the proportion of respondents reporting a history of contact had markedly decreased over these 3 phases in most provinces (Figure 2A, B, and C). This observation was further confirmed by correlation analysis between the proportion of respondents reporting a history of contact and date in areas outside of Wuhan City and Hubei Province (Figure 2D). These findings indicate the efficacy of current policies adopted to reduce the history of contact among the general population since the lockdown in Wuhan and other areas on January 23, 2020. 
Figure 2. The geographic spread of the proportion of respondents reporting a history of contact in three phases of the COVID-19 outbreak (A, B, and C), and its time course in all regions outside Wuhan City and Hubei Province (D).
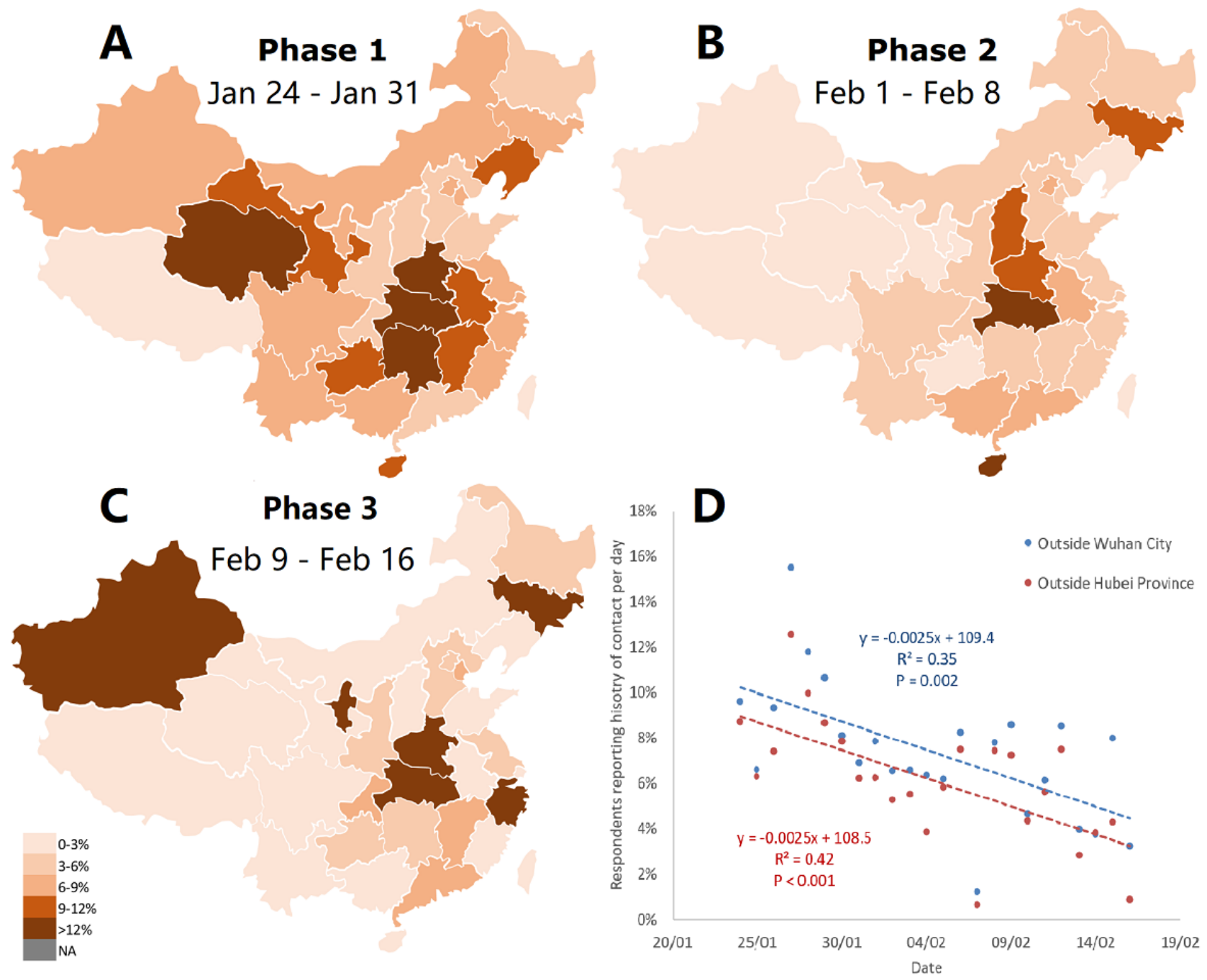

\section{Body Temperature}

Body temperature was measured in $77.49 \%$ ( $n=14,073 / 18,161)$ of respondents, with a higher percentage in Wuhan City $(\mathrm{n}=990 / 1171,84.54 \%)$ and Hubei Province $(\mathrm{n}=1431 / 1710$, $83.68 \%$ ). Overall, fever was reported in less than one-tenth of the respondents. Unexpectedly, a lower percentage was found

for Wuhan City and Hubei Province. This might be due to COVID-19 developing to a further stage in Wuhan, and fever cases were identified early and sent to hospitals without access to the internet. We further analyzed how the percentage of respondents with fever evolved with time. The trend seemed to peak on around February 8, 2020 (Figure 3). 
Figure 3. Proportion of respondents reporting a fever over time.

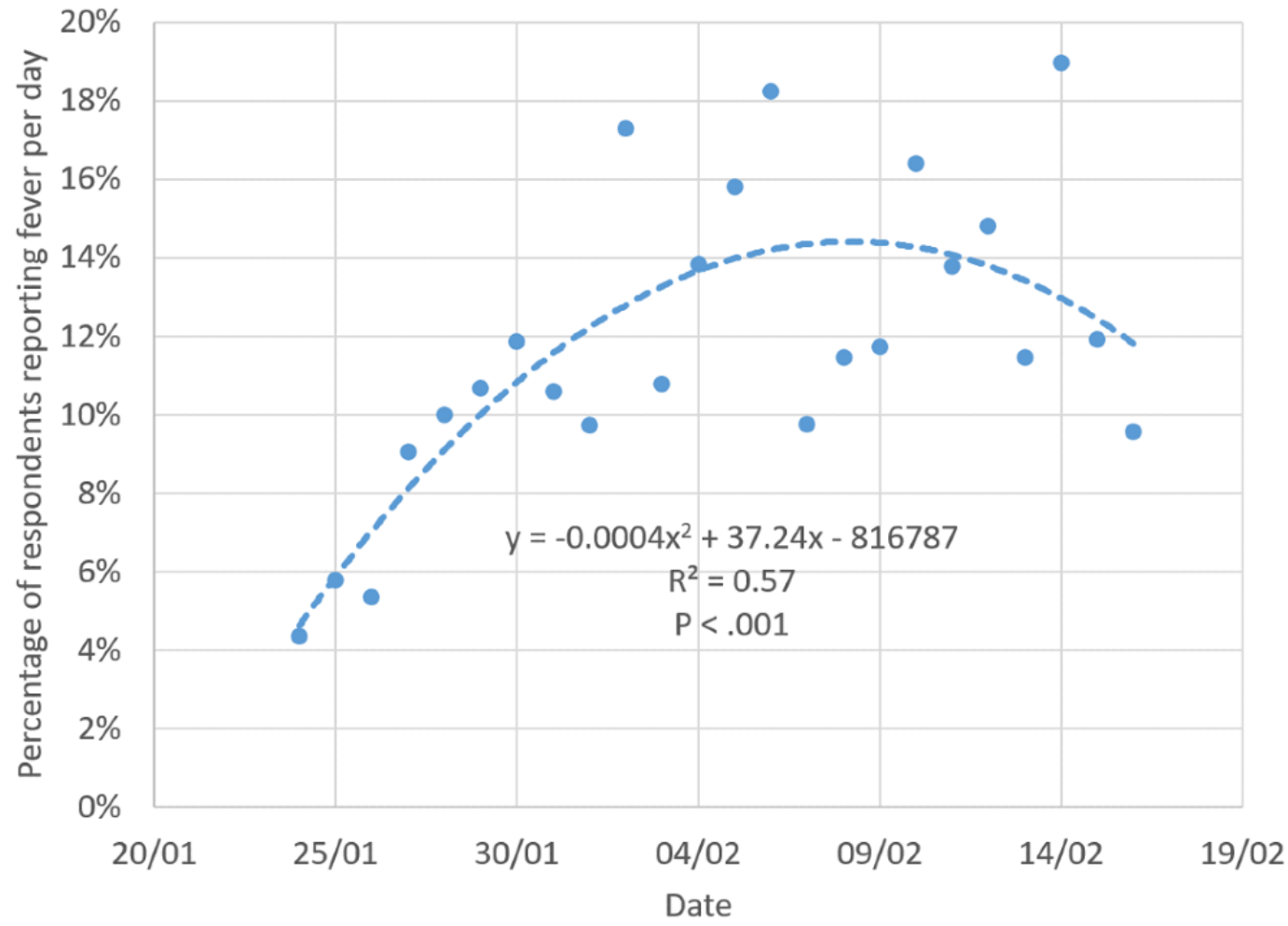

\section{Fever in Respondents With a History of Contact}

Analyzing the relationship between fever and history of contact may help develop population-based strategies for prevention purposes. For the respondents living outside Wuhan, we found a significant relation between any history of contact and fever (RR 1.31, 95\% CI 1.13-1.52, $P<.001$ ). Travelling to Wuhan, having any close contact with a confirmed case, and having at least 2 confirmed cases at the workplace in the past 2 weeks conferred a significantly higher risk of fever (RR 1.47, 95\% CI 1.23-1.77, $P<.001$; RR 1.98, 95\% CI 1.67-2.24, $P<.001$; and RR 2.12, 95\% CI 1.74-2.58, $P<.001$, respectively). Moreover, there was a significant positive relation between the number of officially confirmed cases and the number of respondents reporting a fever $\left(R^{2}=0.41, P<.001\right)$ or the number of respondents reporting a fever and a history of contact $\left(R^{2}=0.35\right.$, $P<.001)$ on a province basis. Regarding risk stratification based on history of contact and fever, most respondents $(n=14,264 / 18,161,78.54 \%)$ were classified in the very low-risk group, followed by the moderate-risk group $(\mathrm{n}=1883,10.37 \%)$ and the low-risk group $(\mathrm{n}=1428,7.86 \%)$, whereas only $1.24 \%$ $(n=225)$ were classified to the high-risk group.

Furthermore, comparison of fever rates among groups of various characteristics was likely to help identify risk factors (Figure 4). Males were at a higher risk of fever than females $(P<.001)$. There was a positive trend between age and fever $(P<.001)$. Respondents reporting fatigue and headache or myalgia were more likely to report fever $(P<.001)$. Comorbidities showed various associations with fever, among which history of lung diseases seemed to confer a higher risk of fever than the others. However, the relationship needs to be further validated by studies with larger samples because of a relatively small number of respondents in each group. 
Figure 4. Fever in various subgroups of respondents with history of contact.

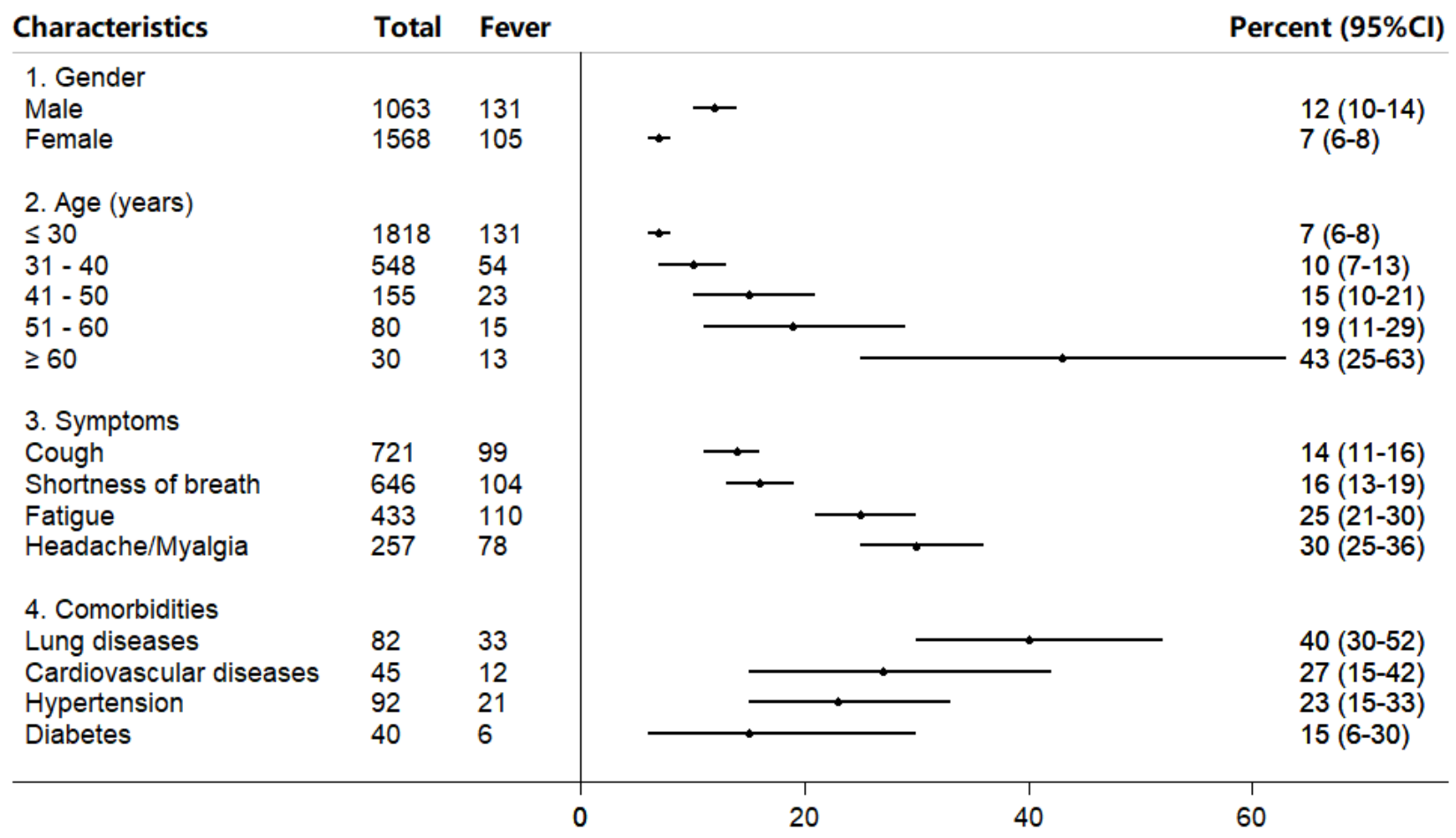

\section{Discussion}

\section{Principal Findings}

To the best of our knowledge, this is the first large-sample online surveillance of the COVID-19 outbreak in the general population. Our major findings include: the questionnaire had a good coverage of all provinces of China in a relatively short period of time (about 3 weeks); the history of contact among the population outside of Wuhan and Hubei Province significantly decreased during the early phase of the government lockdown policy; fever reported by respondents significantly increased in the short-term of the disease outbreak and levelled off in 2-3 weeks; and, among those with history of contact, some factors (male, advanced age, and history of lung diseases) seemed to be associated with a higher risk of fever.

\section{Values of Online Questionnaire}

An online questionnaire is likely to serve as a complementary way of disease surveillance in the general population, especially during the emergent outbreak of an infectious disease [5]. It takes the advantage of low costs and efficient delivery to all areas, even the most remote areas where internet access is better than health care resources [16,17]. Our questionnaire was completed by 385 Chinese respondents from 38 overseas countries, including developed (the United States, Japan, Canada, and the United Kingdom), developing (Brazil, Russia, India, and South Africa), and underdeveloped countries (Laos, Uganda, and Cambodia). Translation of the questionnaire to other languages may further increase the coverage across the world and improve surveillance of the COVID-19 outbreak and comparable epidemics.

Compared with the conventional way of disease surveillance, the online questionnaire covers the population with generally less severe conditions but, nevertheless, is at risk of infection $[7,18]$, taking into account that this population helps to establish the full spectrum of COVID-19 epidemiology. It may also facilitate the early triage and diagnosis of high-risk groups when combined with other digital health measures such as online physician consultation, which has been widely adopted since the COVID-19 outbreak in China. For the low-risk population, the questionnaire can also be adapted to reduce unnecessary anxiety and hospital visits, and thus, greatly relieve the workloads of health care facilities, especially when an emergent public health event occurs [19].

The questionnaire approach is advantageous compared with other approaches of online disease surveillance using data from Google Trends, Twitter, or Facebook [20-22]. It provides richer information of the respondents, as most items can be designed according to medical guidelines and characteristics of target populations. Therefore, it is a more active approach than other infosurveillance methods using social media. The information such as symptoms, history of contact, and comorbidities provided by an online questionnaire can be further combined with vital data such as body temperature, heart rate, respiratory rate, oxygenation level, and activity level obtained from wearable devices to have a more comprehensive and reliable estimation of respondent's risk of disease [23]. For the high-risk group identified using an online questionnaire, a case can be further confirmed by sending a home-testing kit and instructing the respondents to perform a rapid diagnostic test, as shown in the GoViral study [24]. Additionally, self-reported data from an online questionnaire can be linked with electronic medical records to build a long-term monitoring system [8].

\section{Use of Questionnaire to Observe Trends}

An online survey is likely to be used to observe the trends of disease prevalence in communities and, thus, support 
government policy evaluation. In our study, the date February 8,2020 , when the percentage of fever respondents peaked, was 16 days following the lockdown of Wuhan City, which was close to the 14 days of the maximum incubation period of the coronavirus [25]. The delay of the fever peak might be associated with delayed quarantine policies in other cities in China. Overall, our data supported the efficacy of current policies (quarantine, social distancing, and isolation of infected populations) for containing the spread of COVID-19 from Wuhan City to the other areas of China [6,26,27]. However, the period and efficacy of quarantine may differ by country [28]. It depends on not only government policies but also local culture and more importantly active support from the general population. For other countries, which may not have quarantine policies as strict as China, the time to fever peak is probably longer among the general population. Moreover, integration of the survey data into a model for real time and long-term forecasting of disease trends is likely to provide richer information for making policies [29]. Of note, our questionnaire is more applicable to those living in China than abroad. The definition of history of contact has mostly relied on contact with a confirmed case from Wuhan. However, this can be further modified according to the earliest and generally most severely affected area of a country of interest, such as Lombardy in Italy.

\section{Use of Questionnaire to Identify Risk Factors}

Our survey also indicates that some factors such as male, an advanced age, and a history of lung disease are likely to relate to a higher risk of infection, and thus, these groups should be under close observation. Indeed, these risk factors identified from our study are consistent with the clinical features of infected cases in previous publications [9,30-33]. By quickly disseminating an online questionnaire during the early phase of a disease outbreak, risk factors can be identified at a much earlier phase rather than when enough severe cases have been collected and analyzed using a conventional surveillance method. This further allows for earlier protection of vulnerable groups from potential infection and, thus, reduces the number of cases. Internet-based surveillance approaches based on Twitter have been demonstrated to detect Ebola, avian influenza, and thunderstorm asthma at an early stage, even before the first official report [20-22].

\section{Limitations of the Approach}

The approach undoubtedly has the bias of sampling primarily internet users and their relatives. As a consequence, the population included in our study is relatively young. A previous study demonstrated that both too young (age 0-10 years) and too old (age older than 81 years) populations are underrepresented in an internet-based monitoring survey [34]. A better coverage of the general population with high representativeness generally requires a more complicated study design together with robust supports from an official institution [8]. The questionnaire can also be distributed through other web platforms such as Sina Weibo (the most popular microblogging website in China) and news media (NetEase and Xinhua), which have a wider reach of respondents in China. Furthermore, this study does not include a follow-up for individual patients. This choice was made to respect the respondents' privacy. However, in future studies it may be acceptable to allot an individual code to each individual, thereby allowing follow-ups; although, systematic follow-ups will remain a problem with internet questionnaires. Follow-ups may be further compromised by the lack of internet access when the individual is hospitalized.

Unlike hospitals, which diagnose COVID-19 using a comprehensive set of laboratory and imaging examinations, we did not include diagnostic tests such as real time polymerase chain reaction or lung computed tomography results in our questionnaire. Therefore, evaluating the respondents' risk of viral infection from the history of contact, body temperature, symptoms, and comorbidities may have the risk of underestimating some patients who are asymptomatic or presymptomatic, which are not uncommon $[35,36]$.

Based on this study, we have updated our fourth version of the Chinese questionnaire [37] and released the English questionnaire [38] (also see Multimedia Appendices 1 and 2 for Word format files). Both questionnaires follow the Attribution 4.0 International license, meaning that they are free to be shared and adapted under the condition that this work has been properly cited. Considering privacy purposes, the survey data of this study can be obtained from the corresponding author at request.

\section{Conclusions}

This study shows that an online questionnaire may help monitor current prevalence, evaluate government policy, and identify high-risk populations during the COVID-19 outbreak. The online questionnaire approach can also be adapted to monitor other types of infectious diseases depending on areas of interest.

\section{Acknowledgments}

We have received funding from the European Union Horizon 2020 research and innovation program "Personalised In-silico Cardiology (PIC)" under the Marie Sklodowska-Curie grant agreement No 764738. The funding source had no involvement in the study.

We would like to thank the editor and anonymous reviewers for their constructive comments on improving this manuscript.

\section{Conflicts of Interest}

None declared. 


\section{Multimedia Appendix 1}

Coronavirus Infection Risk Self-Assessment Questionnaire (CIRSAQ 4.0).

[DOCX File, 13 KB-Multimedia Appendix 1]

\section{Multimedia Appendix 2}

Coronavirus Infection Risk Self-Assessment Questionnaire (CIRSAQ 4.0) - Chinese Simplified.

[DOCX File, 14 KB-Multimedia Appendix 2]

\section{References}

1. Wu JT, Leung K, Leung GM. Nowcasting and forecasting the potential domestic and international spread of the 2019-nCoV outbreak originating in Wuhan, China: a modelling study. Lancet 2020 Feb 29;395(10225):689-697 [FREE Full text] [doi: 10.1016/S0140-6736(20)30260-9] [Medline: 32014114]

2. Hui DS, I Azhar E, Madani TA, Ntoumi F, Kock R, Dar O, et al. The continuing 2019-nCoV epidemic threat of novel coronaviruses to global health - The latest 2019 novel coronavirus outbreak in Wuhan, China. Int J Infect Dis 2020 Feb;91:264-266 [FREE Full text] [doi: 10.1016/j.ijid.2020.01.009] [Medline: $\underline{\text { 31953166] }}$

3. World Health Organization. WHO announces COVID-19 outbreak a pandemic URL: http://www.euro.who.int/en/ health-topics/health-emergencies/coronavirus-covid-19/news/news/2020/3/who-announces-covid-19-outbreak-a-pandemic

4. Worldometer. Covid-19 coronavirus pandemic URL: https://www.worldometers.info/coronavirus/ [accessed 2020-03-30]

5. Lipsitch M, Swerdlow DL, Finelli L. Defining the Epidemiology of Covid-19 - Studies Needed. N Engl J Med 2020 Mar 26;382(13):1194-1196. [doi: 10.1056/NEJMp2002125] [Medline: $\underline{32074416}$ ]

6. Cheng V, Wong S, To K, Ho PK, Yuen KY. Preparedness and proactive infection control measures against the emerging novel coronavirus in China. J Hosp Infect 2020 Mar;104(3):254-255 [FREE Full text] [doi: 10.1016/j.jhin.2020.01.010] [Medline: 31962139$]$

7. Cowling BJ, Leung GM. Epidemiological research priorities for public health control of the ongoing global novel coronavirus (2019-nCoV) outbreak. Euro Surveill 2020 Feb;25(6) [FREE Full text] [doi: 10.2807/1560-7917.ES.2020.25.6.2000110] [Medline: 32046814]

8. Smolinski MS, Crawley AW, Olsen JM, Jayaraman T, Libel M. Participatory Disease Surveillance: Engaging Communities Directly in Reporting, Monitoring, and Responding to Health Threats. JMIR Public Health Surveill 2017 Oct 11;3(4):e62 [FREE Full text] [doi: 10.2196/publichealth.7540] [Medline: 29021131]

9. Huang C, Wang Y, Li X, Ren L, Zhao J, Hu Y, et al. Clinical features of patients infected with 2019 novel coronavirus in Wuhan, China. Lancet 2020 Feb 15;395(10223):497-506 [FREE Full text] [doi: 10.1016/S0140-6736(20)30183-5] [Medline: 31986264]

10. National Health Commission of China. Report of situations about 2019 coronavirus disease on 23 January 2020 URL: http:/ /www.nhc.gov.cn/xcs/yqtb/202001/5d19a4f6d3154b9fae328918ed2e3c8a.shtml [accessed 2020-01-23]

11. National Health Commission of China. Diagnosis and treatments of new coronavirus pneumonia (Third version) URL: http://www.nhc.gov.cn/xcs/zhengcwj/202001/f492c9153ea9437bb587ce2ffcbee1fa.shtml [accessed 2020-03-05]

12. Questionnaire Star. Homepage of Questionnaire Star Company URL: https://www.wjx.cn/ [accessed 2020-03-05]

13. World Health Organization. 2017 Jan 01. WHO guidelines on ethical issues in public health surveillance URL: https://apps. who.int/iris/bitstream/handle/10665/255721/9789241512657-eng.pdf [accessed 2020-03-05]

14. National Bureau of Statistics China. China Statistical Abstract 2019. Beijing, China: China Statistics Press; 2019.

15. NetEase News. Real-time COVID-19 tracking URL: https://wp.m.163.com/163/page/news/virus report/index. html? nw $=1 \&$ anw $=1$ [accessed 2020-03-05]

16. Flahault A, Utzinger J, Eckerle I, Sheath D, de Castañeda RR, Bolon I, et al. Precision global health for real-time action. The Lancet Digital Health 2020 Feb;2(2):e58-e59. [doi: 10.1016/s2589-7500(19)30240-7]

17. Gilbert M, Pullano G, Pinotti F, Valdano E, Poletto C, Boëlle PY, et al. Preparedness and vulnerability of African countries against importations of COVID-19: a modelling study. Lancet 2020 Mar 14;395(10227):871-877 [FREE Full text] [doi: 10.1016/S0140-6736(20)30411-6] [Medline: 32087820]

18. Zhao S, Musa SS, Lin Q, Ran J, Yang G, Wang W, et al. Estimating the Unreported Number of Novel Coronavirus (2019-nCoV) Cases in China in the First Half of January 2020: A Data-Driven Modelling Analysis of the Early Outbreak. J Clin Med 2020 Feb 01;9(2) [FREE Full text] [doi: 10.3390/jcm9020388] [Medline: 32024089]

19. Wong JEL, Leo YS, Tan CC. COVID-19 in Singapore-Current Experience: Critical Global Issues That Require Attention and Action. JAMA 2020 Feb 20. [doi: 10.1001/jama.2020.2467] [Medline: 32077901]

20. Yousefinaghani S, Dara R, Poljak Z, Bernardo TM, Sharif S. The Assessment of Twitter's Potential for Outbreak Detection: Avian Influenza Case Study. Sci Rep 2019 Dec 03;9(1):18147 [FREE Full text] [doi: 10.1038/s41598-019-54388-4] [Medline: $\underline{31796768]}$

21. Odlum M, Yoon S. What can we learn about the Ebola outbreak from tweets? Am J Infect Control 2015 Jun;43(6):563-571 [FREE Full text] [doi: 10.1016/j.ajic.2015.02.023] [Medline: 26042846] 
22. Joshi A, Sparks R, McHugh J, Karimi S, Paris C, MacIntyre CR. Harnessing Tweets for Early Detection of an Acute Disease Event. Epidemiology 2020 Jan;31(1):90-97 [FREE Full text] [doi: 10.1097/EDE.0000000000001133] [Medline: 31651659]

23. Radin J, Wineinger N, Topol ES, Steinhubl SR. Harnessing wearable device data to improve state-level real-time surveillance of influenza-like illness in the USA: a population-based study. The Lancet Digital Health 2020 Feb;2(2):e85-e93. [doi: 10.1016/s2589-7500(19)30222-5]

24. Goff J, Rowe A, Brownstein JS, Chunara R. Surveillance of Acute Respiratory Infections Using Community-Submitted Symptoms and Specimens for Molecular Diagnostic Testing. PLoS Curr 2015 May 27;7 [FREE Full text] [doi: 10.1371/currents.outbreaks.0371243baa7f3810ba1279e30b96d3b6] [Medline: 26075141]

25. Backer JA, Klinkenberg D, Wallinga J. Incubation period of 2019 novel coronavirus (2019-nCoV) infections among travellers from Wuhan, China, 20-28 January 2020. Euro Surveill 2020 Feb;25(5) [FREE Full text] [doi: 10.2807/1560-7917.ES.2020.25.5.2000062] [Medline: 32046819]

26. Anderson RM, Heesterbeek H, Klinkenberg D, Hollingsworth T. How will country-based mitigation measures influence the course of the COVID-19 epidemic? Lancet 2020 Mar 21;395(10228):931-934 [FREE Full text] [doi: 10.1016/S0140-6736(20)30567-5] [Medline: 32164834]

27. Tang B, Xia F, Tang S, Bragazzi NL, Li Q, Sun X, et al. The effectiveness of quarantine and isolation determine the trend of the COVID-19 epidemics in the final phase of the current outbreak in China. Int J Infect Dis 2020 Mar 11 [FREE Full text] [doi: 10.1016/j.ijid.2020.03.018] [Medline: 32171948]

28. The Lancet. COVID-19: too little, too late? Lancet 2020 Mar 07;395(10226):755 [FREE Full text] [doi: 10.1016/S0140-6736(20)30522-5] [Medline: 32145772]

29. Brownstein JS, Chu S, Marathe A, Marathe MV, Nguyen AT, Paolotti D, et al. Combining Participatory Influenza Surveillance with Modeling and Forecasting: Three Alternative Approaches. JMIR Public Health Surveill 2017 Nov 01;3(4):e83 [FREE Full text] [doi: 10.2196/publichealth.7344] [Medline: 29092812]

30. Chen N, Zhou M, Dong X, Qu J, Gong F, Han Y, et al. Epidemiological and clinical characteristics of 99 cases of 2019 novel coronavirus pneumonia in Wuhan, China: a descriptive study. Lancet 2020 Feb 15;395(10223):507-513 [FREE Full text] [doi: 10.1016/S0140-6736(20)30211-7] [Medline: 32007143]

31. Wang D, Hu B, Hu C, Zhu F, Liu X, Zhang J, et al. Clinical Characteristics of 138 Hospitalized Patients With 2019 Novel Coronavirus-Infected Pneumonia in Wuhan, China. JAMA 2020 Feb 07. [doi: 10.1001/jama.2020.1585] [Medline: 32031570]

32. Xu X, Wu X, Jiang X, Xu K, Ying L, Ma C, et al. Clinical findings in a group of patients infected with the 2019 novel coronavirus (SARS-Cov-2) outside of Wuhan, China: retrospective case series. BMJ 2020 Feb 19;368:m606 [FREE Full text] [doi: 10.1136/bmj.m606] [Medline: 32075786]

33. Yang X, Yu Y, Xu J, Shu H, Xia J, Liu H, et al. Clinical course and outcomes of critically ill patients with SARS-CoV-2 pneumonia in Wuhan, China: a single-centered, retrospective, observational study. Lancet Respir Med 2020 Feb 24 [FREE Full text] [doi: 10.1016/S2213-2600(20)30079-5] [Medline: 32105632]

34. Marquet RL, Bartelds AIM, van Noort SP, Koppeschaar CE, Paget J, Schellevis FG, et al. Internet-based monitoring of influenza-like illness (ILI) in the general population of the Netherlands during the 2003-2004 influenza season. BMC Public Health 2006 Oct 04;6:242 [FREE Full text] [doi: 10.1186/1471-2458-6-242] [Medline: 17018161]

35. Pan X, Chen D, Xia Y, Wu X, Li T, Ou X, et al. Asymptomatic cases in a family cluster with SARS-CoV-2 infection. Lancet Infect Dis 2020 Apr;20(4):410-411 [FREE Full text] [doi: 10.1016/S1473-3099(20)30114-6] [Medline: 32087116]

36. Bai Y, Yao L, Wei T, Tian F, Jin D, Chen L, et al. Presumed Asymptomatic Carrier Transmission of COVID-19. JAMA 2020 Feb 21. [doi: 10.1001/jama.2020.2565] [Medline: 32083643]

37. Luo H, Lie Y, Prinzen F. Coronavirus Infection Risk Self-Assessment Questionnaire (CIRSAQ 4.0, Chinese Simplified). URL: https://ks.wjx.top/jq/59735934.aspx [accessed 2020-03-05]

38. Luo H, Lie Y, Prinzen F. Coronavirus Infection Risk Self-Assessment Questionnaire (CIRSAQ 4.0, English version). URL: https://ks.wjx.top/jq/59730857.aspx [accessed 2020-03-05]

\author{
Abbreviations \\ COVID-19: coronavirus disease \\ RR: risk ratio
}


Edited by T Sanchez; submitted 05.03.20; peer-reviewed by B Dixon, O Leal Neto; comments to author 23.03.20; revised version received 01.04.20; accepted 21.04.20; published 27.04.20

Please cite as:

Luo H, Lie Y, Prinzen FW

Surveillance of COVID-19 in the General Population Using an Online Questionnaire: Report From 18,161 Respondents in China

JMIR Public Health Surveill 2020;6(2):e18576

URL: http://publichealth.jmir.org/2020/2/e18576/

doi: $10.2196 / 18576$

PMID: $\underline{32319956}$

CHongxing Luo, Yongchan Lie, Frits W Prinzen. Originally published in JMIR Public Health and Surveillance (http://publichealth.jmir.org), 27.04.2020. This is an open-access article distributed under the terms of the Creative Commons Attribution License (https://creativecommons.org/licenses/by/4.0/), which permits unrestricted use, distribution, and reproduction in any medium, provided the original work, first published in JMIR Public Health and Surveillance, is properly cited. The complete bibliographic information, a link to the original publication on http://publichealth.jmir.org, as well as this copyright and license information must be included. 